\title{
Colchicine efficacy and safety for the treatment of cardiovascular diseases
}

\author{
Alessandro Andreis ${ }^{1} \cdot{\text { Massimo } \text { Imazio }^{1} \text { (1) } \cdot \text { Matteo Casula }}^{1} \cdot$ Stefano Avondo ${ }^{1} \cdot$ Gaetano Maria De Ferrari $^{1}$
}

Received: 10 November 2020 / Accepted: 22 January 2021 / Published online: 11 March 2021

(c) Società Italiana di Medicina Interna (SIMI) 2021

\begin{abstract}
The emerging role of colchicine in the treatment of cardiovascular diseases is a strong demand for a comprehensive understanding of its efficacy and safety. This meta-analysis and systematic review aimed to study the efficacy in the reduction of adverse cardiovascular outcomes (CO), and the risk of colchicine-related adverse events (CRAEs). Fourteen thousand and nine eighty three patients from 22 randomized controlled trials (RCTs) were included, 9 in patients with coronary artery disease - CAD, 9 in patients with pericarditis, 4 in patients with atrial fibrillation-AF or heart failure. Colchicine was efficacious in the reduction of adverse $\mathrm{CO}$ across different settings: pericardial diseases (reduced risk of recurrent pericarditis, $17.6 \%$ vs. $35 \%$, RR $0.50,95 \%$ CI $0.41-0.61$ ), CAD (reduced risk of cardiac death, myocardial infarction, stroke,coronary revascularization or hospitalization, $6.1 \%$ vs. $8.5 \%$, RR $0.73,95 \% \mathrm{CI} 0.64-0.83$ ), AF (reduced risk of arrhythmia recurrence, $14.2 \%$ vs. $22.7 \%$, RR $0.62,95 \%$ CI $0.44-0.88$ ). Colchicine was associated with increased risk of gastrointestinal CRAEs (11.2\% vs. $8.8 \%$, RR $1.87,95 \%$ CI $1.41-2.47)$ and drug discontinuation (5.4\% vs. $3.7 \%$, RR $1.58,95 \%$ CI $1.25-1.99)$. In both cases, the risk was proportional to the daily dose or duration of treatment, possibly due to early drug discontinuation or tolerance. Other CRAEs (muscle-related, liver,hematologic,cutaneous, infections) were not increased by colchicine, as long as all-cause death $(2.2 \%$ vs. $1.9 \%$, RR $1.11,95 \%$ CI $0.79-1.54)$ or non-cardiovascular death $(1.5 \%$ vs. $1 \%$, RR $1.43,95 \%$ CI 0.93-2.19). Colchicine is efficacious and safe for the treatment of cardiovascular diseases. The risk of gastrointestinal CRAEs and drug discontinuation is not significant if colchicine is used at lower doses ( $0.5 \mathrm{mg}$ daily) or for longer periods of time ( $>6$ months).
\end{abstract}

Keywords Colchicine $\cdot$ Pericarditis $\cdot$ Coronary artery disease $\cdot$ Heart failure $\cdot$ Atrial fibrillation $\cdot$ Adverse events

\section{Introduction}

Known from the past centuries for its anti-inflammatory benefits in patients with Familial Mediterranean Fever (FMF), Behçet's disease, and gout [1], colchicine recently revealed multiple emerging applications in the cardiovascular field [2]. Indeed, colchicine is beneficial in the setting of pericardial diseases and shows promising results in patients with coronary artery disease, heart failure, and arrhythmias [3]. Its peculiar mechanism of action implicates not only interaction with neutrophil function but also Nod-Like Receptor Protein 3 (NLPR3) inflammasome inhibition, with

Massimo Imazio

massimo_imazio@yahoo.it

1 Departement of Medical Sciences, A.O.U. Città della Salute e della Scienza di Torino, University Cardiology, Corso Bramante 88, 10126 Turin, Italy suppression of the release of Interleukin 1 beta (IL-1 beta) and IL-18 and IL-6 [4-7].

However, the growing interest of clinicians for the newer applications of this drug is a strong demand for a comprehensive understanding of its efficacy and safety. This metanalysis and systematic review aimed to assess colchicine efficacy in the reduction of adverse cardiovascular outcomes (CO), and the risk of colchicine-related adverse events (CRAEs), discontinuation, and mortality.

\section{Methods}

This systematic review and metanalysis, performed according to the Preferred Reporting Items for Systematic Reviews and Meta-Analyses (PRISMA) recommendations [8], included all published randomized and controlled trials (RCTs) assessing colchicine in patients with cardiovascular 
diseases. The primary end-point was the efficacy of colchicine in the reduction of adverse $\mathrm{CO}$ across different clinical settings. In RCTs on pericardial diseases, adverse $\mathrm{CO}$ was defined as recurrent pericarditis. In RCTs on coronary artery disease-CAD, were defined as a composite of cardiac death, myocardial infarction (MI), stroke, coronary revascularization, and hospitalization for a cardiovascular reason. In RCTs on atrial fibrillation (AF), were defined as arrhythmia recurrence, while in the unique RCT on heart failure it was defined as NYHA improvement of at least one grade. We also analyzed the occurrence of CRAEs. Events were grouped into categories: gastrointestinal CRAE (including vomiting, nausea, diarrhea, cramping, abdominal pain, anorexia, melena, gastrointestinal hemorrhage), muscle-related CRAE (including myalgias, muscle cramping, abnormally increased creatine kinase), liver CRAE (including abnormally increased aminotransferases and hepatitis), hematologic CRAE (including anemia, leukopenia, thrombocytopenia), cutaneous CRAE (rash, alopecia), CRAE-related drug discontinuation, infections, and death. In case of $\geq 2$ CRAEs reported under the same category, only the event with the highest number of patients was considered for such category.

We searched through databases (Pubmed, Embase, Scopus, MEDLINE, and the Cochrane Library) using the terms "colchicine" AND "safety" AND "cardiovascular diseases" OR "coronary syndromes" OR "coronary artery disease" OR "heart failure" or "arrhythmias". This research was conducted from inception to 31st December 2020. Three independent reviewers (AA, MI, MC) screened titles and abstracts of all studies and the potentially eligible ones were appraised as full-text. The most relevant articles quoted in the studies were also screened. Discrepancies were resolved by consensus.

We excluded studies not performed in humans, with full-text not published in the English language, or without outcomes of interest. The quality of included RCTs was independently assessed by three reviewers (AA, MI, SA) using the modified-Jadad scale assessing 7 items: randomization, blinding, withdrawal, dropout, inclusion/exclusion criteria, adverse events, and statistical analysis. This scale has a maximum score of 8 points (high-quality studies with score $>4$ points). Discrepancies were resolved by consensus among the Authors. Information on publication (author, year of publication), study design, patients clinical setting, patients characteristics (sample size, age, gender), methods (interventions, follow-up duration), and CRAE (number of patients with CRAE, drug discontinuation for CRAE) were extracted from full-text analysis by three independent reviewers (AA, MI, SA), who also assessed the risk of bias.

Statistical pooling was performed according to a random-effect model with the Mantel-Haenszel weighting method, computing risk estimates with $95 \%$ confidence intervals (CI), using Review Manager 5.3 (The Cochrane
Collaboration, the Nordic Cochrane Centre, Copenhagen, Denmark). Standard hypothesis testing was set at the two-tailed 0.05 level. Heterogeneity between studies was assessed by measuring inconsistency using Cochrane $I^{2}$ index ${ }^{12}$, which describes the percentage of total variation across the studies that is due to heterogeneity rather than chance.

\section{Results}

Twenty-two RCTs were included in the present meta-analysis, including a total of 14,983 patients (PRISMA Flow chart in Figure S1-Supplementary Appendix). Quality assessment revealed high quality for the included studies according to the Jadad scale, with a mean score of $7.23 \pm 1$ points (Fig. 1). Among 14,983 pooled patients, 7532 received colchicine while 7451 received a placebo. Patients were aged 60.2 years old (IQR, 53-65), 66\% male gender, and received colchicine for a median period of 12 weeks (IQR, 3-24). The median follow-up was 24 weeks (IQR, 4-84). Nine studies were performed in the setting of coronary artery disease [9-17], nine studies in the setting of pericardial diseases [18-26], one study in patients with heart failure [27], and three studies in patients with atrial fibrillation [28-30].

In the two studies with the largest cohorts (together involving more than 10.000 patients), the patients received a fixed dose of $0.5 \mathrm{mg}$ daily, while in other studies the dose ranged from 0.5 to $2 \mathrm{mg}$, mostly according to body weight $[15,17]$. The main features of included studies are summarized in Table S1—Supplementary Appendix).

\section{Colchicine efficacy in the reduction of adverse cardiovascular outcomes}

Colchicine proved effective in the reduction of adverse $\mathrm{CO}$ across different clinical settings (Fig. 1), although in the single RCT performed in the setting of heart failure showed neutral effects ( $10.7 \%$ vs. $13.7 \%$, RR $0.78,95 \%$ CI $0.42-1.48, p=0.45)$. In RCTs performed in patients with pericarditis, colchicine was effective in the reduction of recurrent pericarditis ( $17.6 \%$ vs. $35 \%$, RR $0.50,95 \%$ CI $\left.0.41-0.61, p<0.0001, I^{2}=21 \%\right)$. In patients with CAD, colchicine was effective in the reduction of a composite endpoint of cardiac death, MI, stroke, coronary revascularization, and hospitalization for the cardiovascular reason $(6.1 \%$ vs. $8.5 \%$, RR $0.73,95 \%$ CI $0.64-0.83, p<0.0001, I^{2}=0 \%$ ). In RCTs in patients with AF, colchicine reduced the risk of arrhythmia recurrence (14.2\% vs. $22.7 \%$, RR $0.62,95 \%$ CI $0.44-0.88, p=0.007, I^{2}=0 \%$ ). 


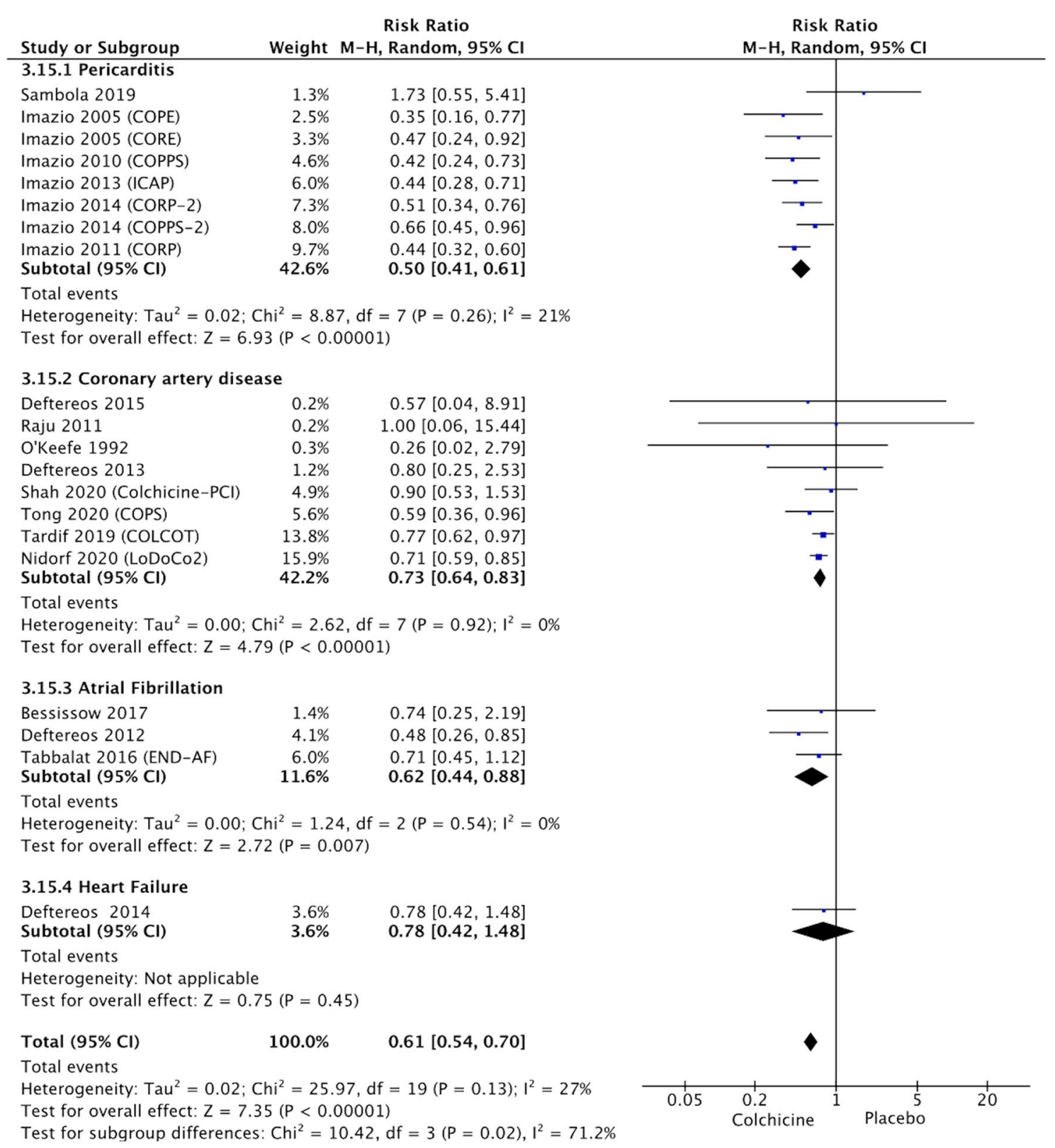

Fig. 1 Forest plot showing colchicine efficacy in the reduction of adverse cardiovascular outcomes, according to the clinical setting

\section{Colchicine-related adverse events}

The occurrence of gastrointestinal CRAEs (including vomiting, nausea, diarrhea, cramping, abdominal pain, anorexia, melena, gastrointestinal hemorrhage) was described in all 22 RCTs. Patients receiving colchicine had an increased risk of gastrointestinal events, as compared with placebo (respectively $11.2 \%$ vs. $8.8 \%$, risk ratio-RR $1.87,95 \%$ CI $1.41-2.47, p<0.0001, I^{2}=71 \%$, Fig. 2). However, the risk of gastrointestinal CRAEs was proportional to treatment duration and the daily dose of colchicine $(\mathrm{p}<0.0001$ among subgroups, as shown in
Fig. 3). Indeed, patients receiving colchicine for a longer period of time ( $>6$ months) did not have a significantly increased risk of gastrointestinal events (RR 1.02, 95\% CI $0.91-1.13, p=0.78, I^{2}=0 \%$ ) as opposed to those treated for 1 to 6 months (RR $1.83,95 \%$ CI $1.16-2.88$, $p=0.009, I^{2}=44 \%$ ) or less than 1 month (RR 2.87, 95\% CI 2.09-3.92, $p<0.0001, I^{2}=4 \%$ ). Similarly, a lower daily dose of colchicine ( $0.5 \mathrm{mg}$ daily) was not associated with an increased risk of gastrointestinal events (RR $1.02,95 \%$ CI $\left.0.91-1.13, p=0.78, I^{2}=0 \%\right)$ as opposed to a higher dose ranging $0.6-1 \mathrm{mg}$ daily (RR $2.09,95 \% \mathrm{CI}$ $1.47-2.97, p<0.0001, I^{2}=43 \%$ ) or even higher $>1 \mathrm{mg}$ 


\begin{tabular}{|c|c|c|c|c|c|}
\hline \multirow[b]{2}{*}{ Study or Subgroup } & \multirow{2}{*}{\multicolumn{2}{|c|}{$\begin{array}{c}\text { Risk Ratio } \\
\text { Weight } \mathrm{M}-\mathrm{H} \text {, Random, } 95 \% \mathrm{Cl} \\
\end{array}$}} & \multirow{2}{*}{\multicolumn{2}{|c|}{$\begin{array}{c}\text { Risk Ratio } \\
\mathrm{M}-\mathrm{H}, \text { Random, } 95 \% \mathrm{Cl} \\
\end{array}$}} & Risk of Bias \\
\hline & & & & & A B C D E F G H \\
\hline Bessissow 2017 & $1.5 \%$ & $5.20[0.63,42.96]$ & & & \\
\hline Deftereos 2014 & $6.0 \%$ & $2.58[1.29,5.15]$ & & - & \\
\hline Deftereos 2012 & $1.5 \%$ & $6.91[0.87,54.92]$ & & & + \\
\hline Deftereos 2013 & $5.1 \%$ & $2.24[0.96,5.24]$ & & ए & \\
\hline Deftereos 2015 & $1.6 \%$ & $14.42[1.95,106.40]$ & & & \\
\hline Giannopoulos 2015 & $1.5 \%$ & $4.83[0.60,38.90]$ & & & \\
\hline Imazio 2005 (COPE) & $3.2 \%$ & $1.25[0.35,4.43]$ & & - & \\
\hline Imazio 2005 (CORE) & $3.0 \%$ & $0.50[0.13,1.87]$ & & E & \\
\hline Imazio 2010 (COPPS) & $5.2 \%$ & $2.00[0.88,4.56]$ & & 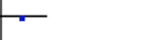 & \\
\hline Imazio 2011 (CORP) & $2.6 \%$ & $1.33[0.31,5.70]$ & & - & \\
\hline Imazio 2013 (ICAP) & $5.2 \%$ & $1.10[0.49,2.49]$ & & - & \\
\hline Imazio 2014 (COPPS-2) & $6.3 \%$ & $2.17[1.13,4.16]$ & & - & $\oplus+$ \\
\hline Imazio 2014 (CORP-2) & $4.8 \%$ & $1.00[0.41,2.43]$ & & - & \\
\hline Liebenberg 2016 & $0.9 \%$ & $17.25[1.10,270.14]$ & & & \\
\hline Nidorf 2020 (LoDoCo2) & $8.1 \%$ & $1.06[0.72,1.55]$ & & - & \\
\hline O'Keefe 1992 & $3.7 \%$ & $6.18[1.98,19.34]$ & & $\longrightarrow$ & \\
\hline Raju 2011 & $5.4 \%$ & $2.00[0.90,4.43]$ & & 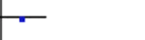 & \\
\hline Sambola 2019 & $3.7 \%$ & $1.73[0.55,5.41]$ & & 5 & \\
\hline Shah 2020 (Colchicine-PCI) & $6.2 \%$ & $2.94[1.51,5.71]$ & & - & \\
\hline Tabbalat 2016 (END-AF) & $6.3 \%$ & $4.45[2.31,8.56]$ & & - & \\
\hline Tardif 2019 (COLCOT) & $9.4 \%$ & $0.99[0.88,1.12]$ & & & \\
\hline Tong 2020 (COPS) & $8.8 \%$ & $1.10[0.85,1.44]$ & & & $+\hookrightarrow+$ \\
\hline Total $(95 \% \mathrm{Cl})$ & $100.0 \%$ & $1.87[1.41,2.47]$ & & $\bullet$ & \\
\hline \multicolumn{6}{|l|}{ Total events } \\
\hline $\begin{array}{l}\text { Heterogeneity: } \operatorname{Tau}^{2}=0.2 \\
\text { Test for overall effect: } Z=\end{array}$ & $\begin{array}{l}i^{2}=73 \\
(P<0\end{array}$ & $\begin{array}{l}5, \mathrm{df}=21(\mathrm{P}<0.00001) ; I^{2}=71 \% \\
001)\end{array}$ & $\begin{array}{l}0.11 \\
\text { Placebo }\end{array}$ & $\begin{array}{c}10 \\
\text { Colchicine }\end{array}$ & 1000 \\
\hline
\end{tabular}

\footnotetext{
Risk of bias legend

(A) Random sequence generation (selection bias)

(B) Allocation concealment (selection bias)

(C) Blind study

(D) Blinding method appropriate

(E) Reporting of withdrawals and dropouts

(F) Presentation of inclusion/exclusion criteria

(G) Method for the assessment of adverse events

(H) Statistical analysis
}

Fig. 2 Forest plot showing the risk of gastrointestinal CRAE with colchicine treatment compared with placebo

daily (RR 3.16, 95\% CI 1.92-5.20, $p<0.0001, I^{2}=0 \%$ ). This finding is in agreement with the large study by Nidorf et al., in which no differences were found in the rate of hospitalizations for gastrointestinal causes, among patients receiving a low-dose regimen of colchicine [17]. The main gastrointestinal event reported in 12 studies was diarrhea (incidence of $12.4 \%$ vs. $8 \%$, RR $2.77,95 \%$ CI $1.55-4.94, p=0.0006, I^{2}=77 \%$ ). Additional subgroup analyses did not show differences according to the use of loading dose ( $p=0.68$ between groups), despite the very mild trend towards increased risk in RCTs adopting a loading dose compared to others (respectively RR $2.05,95 \%$ CI $1.15-3.63, p=0.01$ vs. RR $1.78,95 \%$ CI $1.26-2.51$, $p=0.001$ ). The assessment of gastrointestinal CRAEs according to clinical setting (reported in Figure S3-Supplementary Appendix) showed that in patients with atrial fibrillation (RR 4.67, 95\% CI 2.57-8.51, $p<0.0001$ ) or heart failure (RR 2.58, 95\% CI 1.29-5.15, $p=0.007$ ) the risk was even higher compared to patients with coronary artery disease (RR $1.71,95 \%$ CI $1.20-2.43, p=0.003)$ or pericarditis (RR 1.47, 95\% CI 1.03-2.11, $p=0.04$ ).

Muscle-related CRAEs were reported by 14 studies and included myalgias, muscle cramping, and abnormally increased creatine kinase. Overall, patients on colchicine did not have an increased risk of such events compared to placebo (respectively $7.2 \%$ vs. $6.1 \%$, RR $1.16,95 \%$ CI $0.90-1.50, p=0.25, I^{2}=4 \%$ ), although a recent study reported an increased rate of myalgias in patients receiving colchicine (cumulative incidence ratio $1.15,95 \% \mathrm{CI}$ 1.01-1.31) [17].

The incidence of liver CRAEs (including hepatitis, abnormally increased aminotransferases), hematologic CRAE (including anemia, thrombocytopenia, leukopenia) or cutaneous CRAE (alopecia, rash) was not significantly increased in patients receiving colchicine, as shown in Table 1. However, it should be observed that severe hepatic or renal impairment was an exclusion criterion in all RCTs considered. 

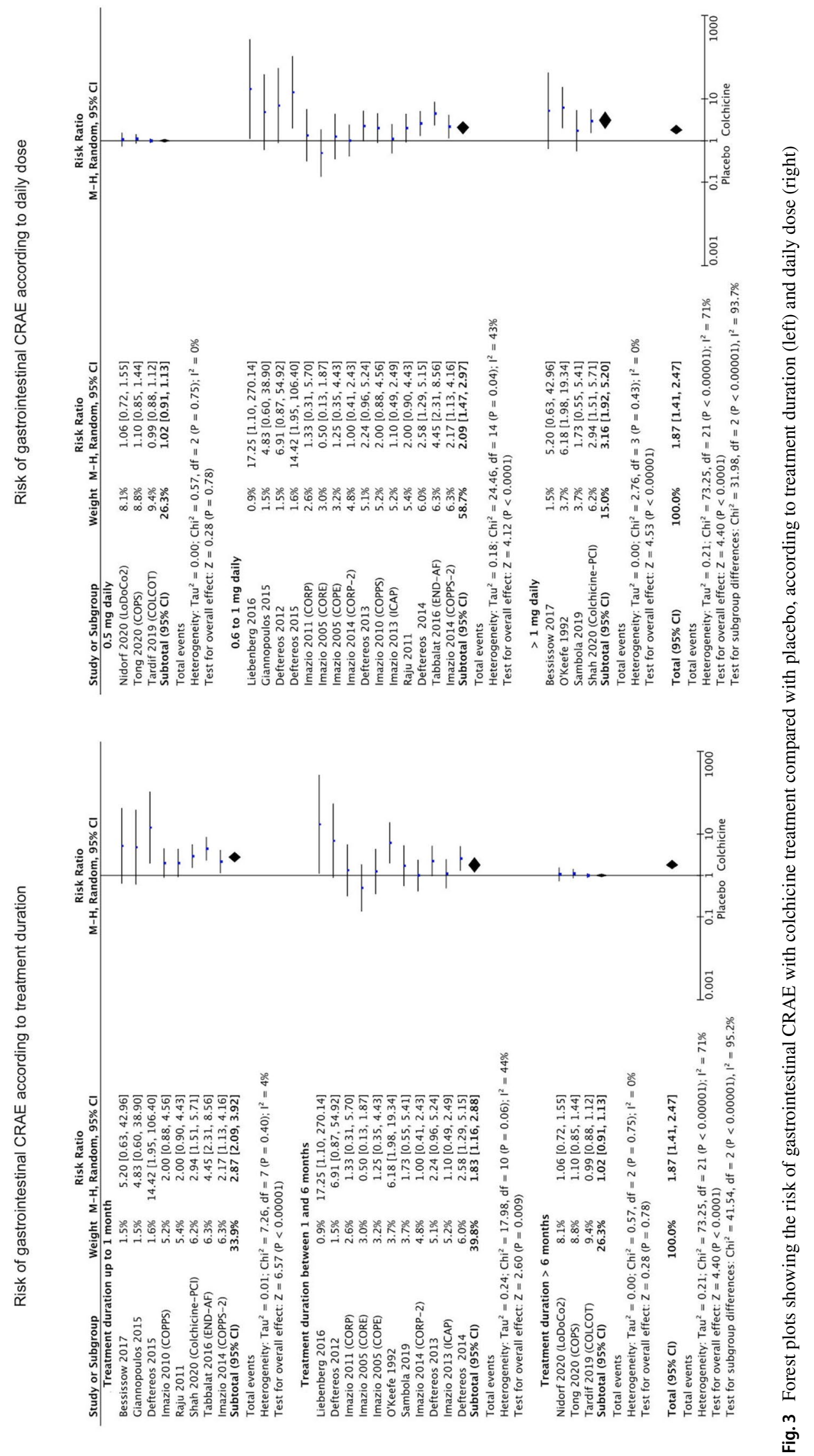
Table 1 Colchicine-related adverse events (CRAEs) in RCTs

\begin{tabular}{|c|c|c|c|c|c|c|}
\hline & No. of RCTs & $\begin{array}{l}\text { COLCHICINE } \\
\text { patients with } \\
\text { event, } \%\end{array}$ & $\begin{array}{l}\text { PLACEBO } \\
\text { Patients with } \\
\text { event, } \%\end{array}$ & $\begin{array}{l}\text { Pooled risk ratio }[95 \% \\
\mathrm{CI}]\end{array}$ & $\begin{array}{l}\text { Overall effect, } \mathrm{Z} \text { ( } p \\
\text { value) }\end{array}$ & Heterogeneity \\
\hline Gastrointestinal & 22 & $847 / 7532,11.2 \%$ & $655 / 7451,8.8 \%$ & $1.87[1.41-2.47]$ & $4.40(<0.0001)$ & $71 \%$ \\
\hline Muscle-related & 14 & $402 / 5775,7 \%$ & $353 / 5785,6.1 \%$ & $1.16[0.90-1.50]$ & $1.16(0.25)$ & $4 \%$ \\
\hline Liver & 12 & $11 / 1298,0.8 \%$ & $6 / 1287,0.5 \%$ & $1.60[0.62-4.10]$ & $0.97(0.33)$ & $0 \%$ \\
\hline Hematologic & 11 & $18 / 6327,0.3 \%$ & $13 / 6338,0.2 \%$ & $1.39[0.68-2.84]$ & $0.91(0.36)$ & $0 \%$ \\
\hline Cutaneous & 11 & $5 / 1598,0.3 \%$ & $15 / 1537,1 \%$ & $0.60[0.17-2.04]$ & $0.82(0.41)$ & $12 \%$ \\
\hline Infections & 3 & $240 / 5141,4.7 \%$ & $245 / 5157,4.7 \%$ & $1.02[0.77-1.34]$ & $0.13(0.90)$ & $32 \%$ \\
\hline All-cause death & 8 & $129 / 5844,2.2 \%$ & $111 / 5791,1.9 \%$ & $1.11[0.79-1.54]$ & $0.60(0.55)$ & $15 \%$ \\
\hline $\begin{array}{l}\text { Non cardiovascular } \\
\text { death }\end{array}$ & 3 & $81 / 5488,1.5 \%$ & $55 / 5505,1 \%$ & $1.43[0.93-2.19]$ & $1.62(0.10)$ & $20 \%$ \\
\hline Drug discontinuation & 18 & $376 / 6919,5.4 \%$ & $256 / 6857,3.7 \%$ & 1.58 [1.25-1.99] & $3.81(0.001)$ & $35 \%$ \\
\hline Any adverse event & 12 & $484 / 3170,15.3 \%$ & $639 / 3971,16 \%$ & $1.07[0.92-1.25]$ & $0.84(0.40)$ & $24 \%$ \\
\hline
\end{tabular}

\section{Infections and mortality}

In the present meta-analysis, eight studies reported the rate of all-cause death and 3 studies reported the rate of noncardiovascular death. Colchicine was not associated with increased risk of all-cause death (2.2\% vs. $1.9 \%$, RR 1.11 , $95 \%$ CI $0.79-1.54, p=0.55, I^{2}=15 \%$ ), nor was significantly associated with non-cardiovascular death $(1.5 \%$ vs. $1 \%$, RR $1.43,95 \%$ CI $0.93-2.19, p=0.10, I^{2}=20 \%$ ), as shown in Fig. 4. The occurrence of infections was assessed and reported in 3 studies and was not associated with colchicine treatment as compared to placebo (respectively $4.7 \%$ vs. $4.8 \%$, RR $1.02,95 \%$ CI $0.77-1.34, p=0.90, I^{2}=32 \%$ ).

\section{Colchicine discontinuation for colchicine-related adverse events}

Among 18 studies reporting colchicine discontinuation, it was observed an increased risk of withdrawal from treatment because of CRAEs (5.4\% vs. 3.7\%, RR $1.58,95 \%$
Fig. 4 Forest plots showing the risk of all-cause death and non-cardiovascular death with colchicine treatment compared with placebo

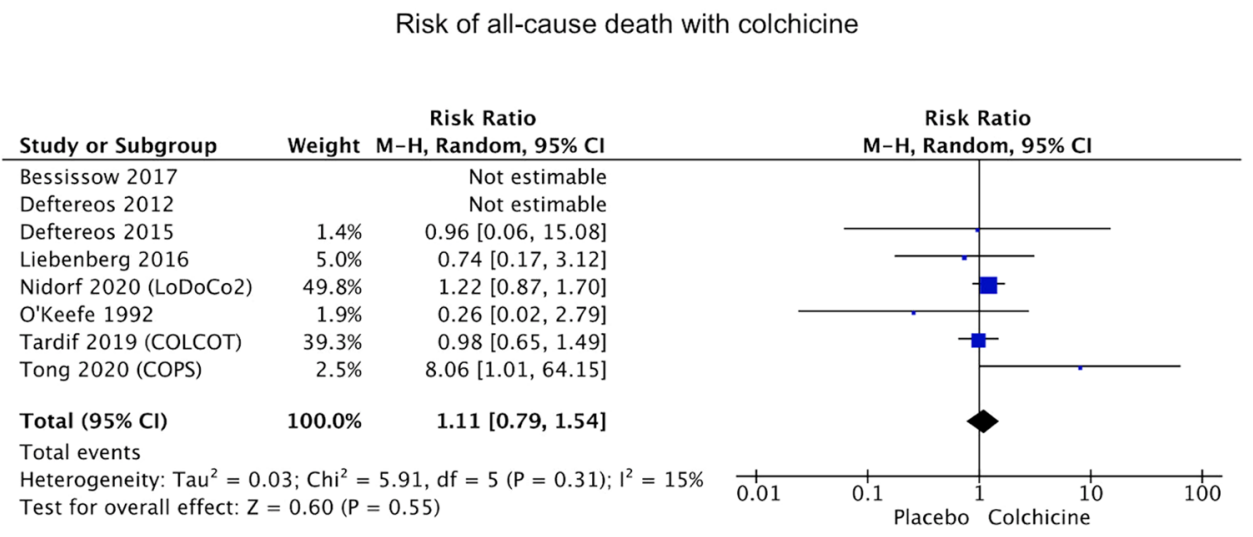

Risk of non-cardiovascular death with colchicine

\begin{tabular}{|c|c|c|c|c|c|}
\hline Study or Subgroup & Weight & $\begin{array}{c}\text { Risk Ratio } \\
\text { M-H, Random, } 95 \% \mathrm{Cl} \\
\end{array}$ & & $\begin{array}{c}\text { Risk Ratio } \\
\mathrm{M}-\mathrm{H}, \text { Random, } 95 \% \mathrm{Cl}\end{array}$ & \\
\hline Nidorf 2020 (LoDoCo2) & $59.8 \%$ & $1.51[0.99,2.31]$ & & & \\
\hline Tardif 2019 (COLCOT) & $38.1 \%$ & $1.16[0.64,2.10]$ & & & \\
\hline Tong 2020 (COPS) & $2.2 \%$ & $11.08[0.61,199.77]$ & & & \\
\hline Total $(95 \% \mathrm{Cl})$ & $100.0 \%$ & $1.43[0.93,2.19]$ & & & \\
\hline \multicolumn{6}{|c|}{ Total events } \\
\hline \multicolumn{3}{|c|}{$\begin{array}{l}\text { Heterogeneity: } \mathrm{Tau}^{2}=0.03 ; \mathrm{Chi}^{2}=2.51, \mathrm{df}=2(\mathrm{P}=0.29) ; \mathrm{I}^{2}=20 \% \\
\text { Test for overall effect: } \mathrm{Z}=1.62(\mathrm{P}=0.10)\end{array}$} & 0.005 & 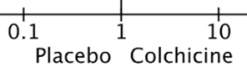 & 200 \\
\hline
\end{tabular}


CI $1.25-1.99, p=0.0001, I^{2}=35 \%$ ), as shown in Fig. 5 . Subgroup analysis showed that for patients on a low-dose regimen ( $0.5 \mathrm{mg}$ daily) or longer treatments ( $>6$ months) the risk was not increased (Figure S2-Supplementary Appendix). Additional subgroup analyses showed that in RCTs adopting a loading dose, compared to other studies, there was an higher risk of discontinuation (respectively RR $2.21,95 \%$ CI $1.39-3.52, p=0.0008$ vs. RR $1.26,95 \%$ CI $1.03-1.54, p=0.02)$.

\section{Discussion}

The beneficial effects of colchicine in the treatment of cardiovascular diseases have been shown in this metanalysis, especially in the setting of pericardial diseases where its use may halve the risk of recurrent pericarditis. Indeed colchicine use is recommended by current European Society of Cardiology Guidelines as a first choice treatment in the setting of acute and recurrent pericarditis [46]. Furthermore, recent data showed that in the challenging scenario of corticosteroid-dependent and colchicine-resistant recurrent pericarditis, colchicine may act as a synergistic agent in association with the innovative anti IL-1 drugs [47],4.

A recently emerging use of colchicine is in the setting of chronic and coronary syndromes. In these patients, colchicine administration is effective in the reduction of adverse $\mathrm{CO}$. This may be explained by colchicine effects on inflammatory cytokines involved in atherosclerotic plaque growth and rupture [48], 49.
Encouraging data presented in the present analysis suggest the possible efficacy of colchicine in the prevention of AF recurrences, mainly driven by the single study of Deftereos et al. [29]. The efficacy of colchicine in this setting could be due to underlying inflammatory mechanisms which, however, are currently not entirely elucidated.

In the setting of heart failure, despite positive results in animal models, in the single RCT performed in humans, it was associated with neutral results [27, 50, 51]. Further larger studies are needed to investigate possible applications in this clinical setting.

The present meta-analysis, assessing 14,983 pooled patients, shows that colchicine use for the treatment of cardiovascular diseases is associated with increased risk of gastrointestinal CRAEs (especially diarrhea) and CRAErelated drug discontinuation (mainly for gastrointestinal symptoms) compared to placebo, although not associated with other CRAEs (muscle-related, liver, hematologic, cutaneous, infections) or all-cause death. However, it should be observed that in patients on a lower daily dose $(0.5 \mathrm{mg}$ daily) and those receiving colchicine for longer periods of time ( $>6$ months), the risk of gastrointestinal CRAEs is similar to placebo. On the contrary, a greater daily dose is directly associated with an increased risk of gastrointestinal CRAEs: the risk is more than doubled for doses ranging 0.6 to $1 \mathrm{mg}$ daily (RR 2.09), more than tripled for doses $>1 \mathrm{mg}$ daily (RR 3.16). Similarly, a shorter duration of treatment is associated with an increased risk of CRAE (respectively RR 1.83 if equal or inferior to 6 months and RR 2.87 if

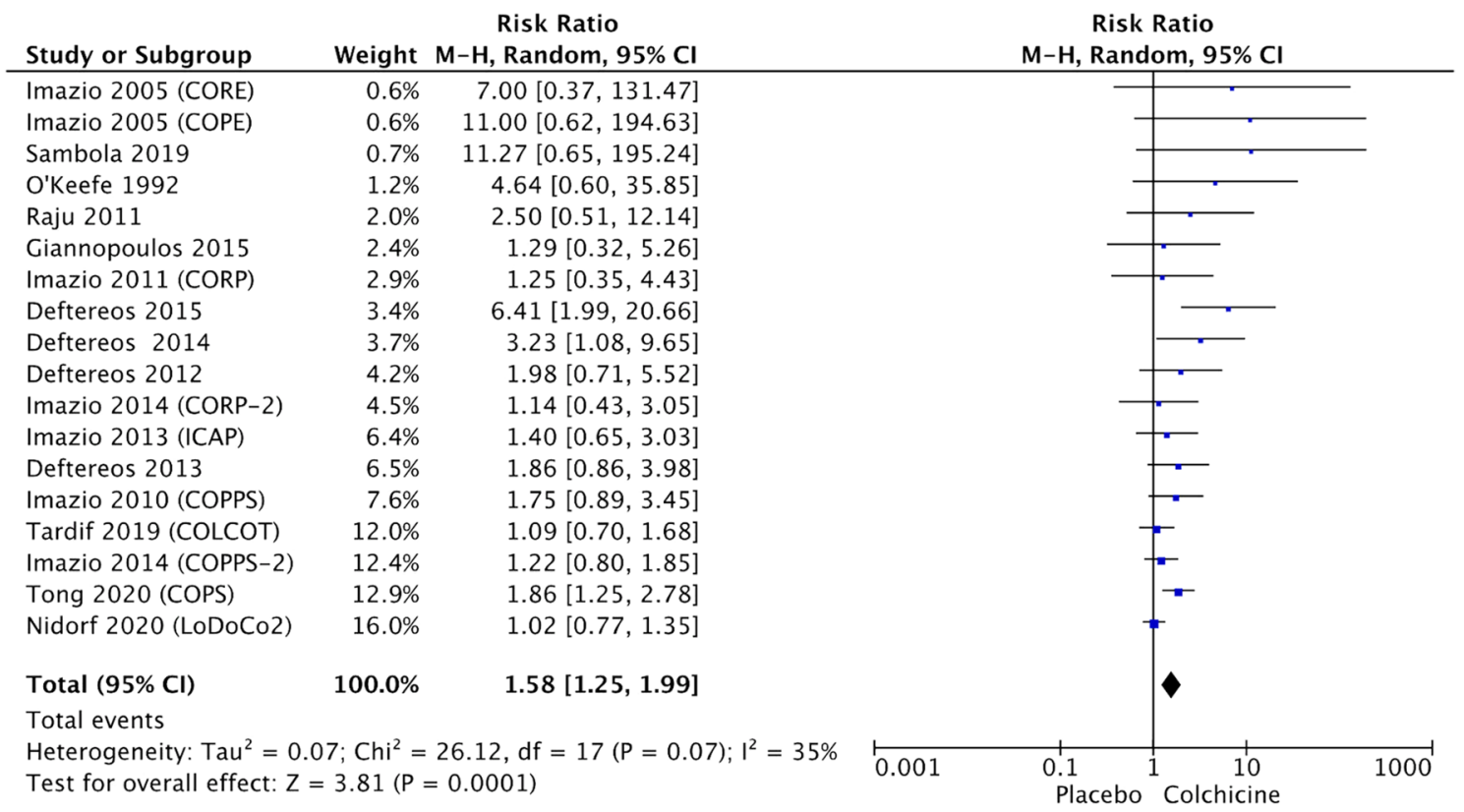

Fig. 5 Forest plots showing the risk of colchicine discontinuation 
equal or inferior to 1 month). Likewise, the risk of CRAErelated drug discontinuation is proportionally associated with dose and duration of treatment (Figure S2-Supplementary Appendix). The use of a loading dose is associated with a further increased risk of discontinuation. Different clinical settings may be apparently associated with some differences in the risk of gastrointestinal CRAEs (Figure S3-Supplementary Appendix). However, it is likely that such differences are essentially driven by the different colchicine regimens used.

Gastrointestinal intolerance to colchicine is transient [31]. This could explain why the risk of discontinuation decreases with longer periods of treatment. Indeed, in patients with FMF, Behcet or osteoarthritis, long-duration treatments ( $>1$ year) have been reported in patients who tolerate colchicine [32-34]. In case of gastrointestinal symptoms when colchicine is started, it may be useful to temporarily split the daily dose, reduce dairy intake and add spasmolytic and antidiarrheal agents to the treatment [31]. Gastrointestinal effects of colchicine are not surprising, considering its mechanism of action. Since colchicine is a microtubule-disassembling (antitubulin) agent, it directly affects mitosis and cell replication processes [35]. Cells with a high turnover, such as those of the gastrointestinal tract, are highly susceptible to colchicine effects $[36,37]$. Indeed in an animal model, excess administration caused intestinal barrier disruption and endotoxin shock due to lipopolysaccharide entering blood flow [36, 38, 39]. The therapeutic index of colchicine is low, with effective plasma concentrations ranging $0.5-3 \mathrm{ng} / \mathrm{ml}$ and toxic effects developing with concentrations beyond $3 \mathrm{ng} / \mathrm{ml}$ [31]. Indeed colchicine overdose may have life-threatening consequences, with cardiac arrhythmias and hemodynamic instability, mediated by interaction with myocardial cell tubulin [40].

The use of colchicine in patients with FMF, Behçet's or gout has been rarely associated with myotoxicity [41, 42]. However, this may occur especially in the case of renal failure, increasing plasma level beyond critical concentrations. In this study, colchicine was not associated with musclerelated CRAEs, although it should be observed that severe renal and hepatic impairment was an exclusion criterion in all RCTs. Indeed an increased risk of myalgias without creatine kinase elevation was observed in a recent large study [17].

Some recent studies raised concerns about the fact that colchicine might increase the risk of non-cardiovascular death $[9,17]$. In fact, in both the COPS trial and LoDoCo2 trial, a trend towards a higher rate of non-cardiovascular deaths was observed in patients on colchicine treatment, compared to placebo. However, in the COPS trial, the authors recommended cautious interpretation of mortality data since the number of patients lost to follow-up was similar to the number of deaths analyzed. In the LoDoCo2 trial the authors hypotesized that such rates could have been due to chance, although being of potential concern. In the present metanalysis, no significant differences were observed among three studies assessing the risk of noncardiovascular death (Fig. 3), although a mild trend was observed. In the CANTOS trial, assessing canakinumab as an antiinflammatory agent targeting IL-1, the increased rate of non-cardiovascular deaths was ascribed to the higher risk of infections and cancer [43]. However, among the studies on colchicine, despite the COLCOT trial reported an increased risk of pneumonia $(p=0.03)$, in the LoDoCo2 there were no differences in the rates of pneumonia, other infections or cancer [15], 17. Indeed the present metanalysis shows that colchicine does not increase the risk of infections. On the contrary, in the context of the recent outbreak of SARS-CoV2 infection, not only IL-1 inhibition is gaining attention as a possible therapeutic strategy but colchicine can be used without risks for the treatment of associated pericardial diseases [44, 45]. However, future studies are warranted to further explore the issue of non-cardiovascular mortality.

This metanalysis has some limitations. First of all, CRAE occurrence was not the primary endpoint in all the RCTs assessed. Furthermore, different definitions were used across different studies. Another limitation of this metanalysis is that the assessment of CRAEs according to colchicine daily dose may have been hindered by the fact that in several RCTs colchicine dose was weight-adjusted (ranging 0.5-2 mg). However, this metanalysis included only RCTs studies, which were judged of high-quality according to Jadad scale.

\section{Conclusions}

Based upon high-quality RCTs, this metanalysis shows that colchicine use is efficacious and safe for the treatment of cardiovascular diseases. Colchicine was efficacious in the reduction of adverse $\mathrm{CO}$ across different settings: pericardial diseases (reduced risk of recurrent pericarditis, $17.6 \%$ vs. $35 \%$, RR $0.50,95 \%$ CI $0.41-0.61$ ), CAD (reduced risk of cardiac death, myocardial infarction, stroke,coronary revascularization or hospitalization, $6.1 \%$ vs. $8.5 \%$, RR $0.73,95 \%$ CI 0.64-0.83), $\mathrm{AF}$ (reduced risk of arrhythmia recurrence, $14.2 \%$ vs. $22.7 \%$, RR $0.62,95 \%$ CI $0.44-0.88$ ). The risk of gastrointestinal CRAEs and drug discontinuation is not significant if colchicine is used at lower doses ( $0.5 \mathrm{mg}$ daily) or for longer periods of time ( $>6$ months). This may be possibly due to early drug discontinuation or drug tolerance. Colchicine is not associated with increased risk of other CRAEs such as muscle-related, liver, hematologic, cutaneous, infections or death. 
Supplementary Information The online version contains supplementary material available at https://doi.org/10.1007/s11739-021-02654-7.

Funding None.

\section{Compliance with ethical standards}

Conflict of interest The authors declared that they have no conflict of interest.

Human and animal rights This study is a meta-analysis and did not involve animals.

Informed consent Original studies included in the meta-analysis obtained EC approval and patient informed consent.

\section{References}

1. Karamanou M, Tsoucalas G, Pantos K, Androutsos G (2018) Isolating colchicine in 19th century: an old drug revisited. Curr Pharm Des 24:654-658. https://doi.org/10.2174/1381612824 666180115105850

2. Slomski A (2020) Colchicine reduces cardiovascular events in chronic coronary disease. JAMA 324:1599. https://doi. org/10.1001/jama.2020.20646

3. Webb CA, Barry AR (2020) Colchicine for secondary cardiovascular prevention: a systematic review. Pharmacotherapy. https:// doi.org/10.1002/phar.2401

4. Opstal TSJ, Hoogeveen RM, Fiolet ATL et al (2020) Colchicine attenuates inflammation beyond the inflammasome in chronic coronary artery disease: a LoDoCo 2 proteomic substudy. Circulation 142:1996-1998. https://doi.org/10.1161/CIRCULATIO NAHA.120.050560

5. Slobodnick A, Shah B, Krasnokutsky S, Pillinger MH (2018) Update on colchicine, 2017. Rheumatol (Oxf) 57:i4-i11. https:// doi.org/10.1093/rheumatology/kex453

6. Groslambert M, Py BF (2018) Spotlight on the NLRP3 inflammasome pathway. J Inflamm Res 11:359-374. https://doi.org/10.2147/ JIR.S141220

7. Andreis A, Imazio M, De Ferrari GM (2020) Colchicine for the treatment of cardiovascular diseases: old drug, new targets. J Cardiovasc Med (Hagerstown). https://doi.org/10.2459/JCM.00000 00000001079

8. Liberati A, Altman DG, Tetzlaff J et al (2009) The PRISMA statement for reporting systematic reviews and meta-analyses of studies that evaluate health care interventions: explanation and elaboration. PLoS Med 6:e1000100. https://doi.org/10.1371/journ al.pmed. 1000100

9. Tong DC, Quinn S, Nasis A et al (2020) Colchicine in patients with acute coronary syndrome: the Australian COPS randomized clinical trial. Circulation. https://doi.org/10.1161/CIRCULATIO NAHA.120.050771

10. Shah B, Pillinger M, Zhong $\mathrm{H}$ et al (2020) Effects of acute colchicine administration prior to percutaneous coronary intervention: COLCHICINE-PCI Randomized Trial. Circ Cardiovasc Interv 13:e008717. https://doi.org/10.1161/CIRCINTERVENTIO NS.119.008717

11. Deftereos S, Giannopoulos G, Raisakis K et al (2013) Colchicine treatment for the prevention of bare-metal stent restenosis in diabetic patients. J Am Coll Cardiol 61:1679-1685. https://doi. org/10.1016/j.jacc.2013.01.055
12. Spyridon D, Georgios G, Christos A et al (2015) Anti-Inflammatory treatment with colchicine in acute myocardial infarction. Circulation 132:1395-1403. https://doi.org/10.1161/CIRCULATIO NAHA.115.017611

13. Giannopoulos G, Angelidis C, Kouritas VK et al (2015) Usefulness of colchicine to reduce perioperative myocardial damage in patients who underwent on-pump coronary artery bypass grafting. Am J Cardiol 115:1376-1381. https://doi.org/10.1016/j.amjca rd.2015.02.036

14. O'Keefe JH, McCallister BD, Bateman TM et al (1992) Ineffectiveness of colchicine for the prevention of restenosis after coronary angioplasty. J Am Coll Cardiol 19:1597-1600. https://doi. org/10.1016/0735-1097(92)90624-v

15. Tardif J-C, Kouz S, Waters DD et al (2019) Efficacy and safety of low-dose colchicine after myocardial infarction. N Engl J Med 381:2497-2505. https://doi.org/10.1056/NEJMoa1912388

16. Raju NC, Yi Q, Nidorf M et al (2012) Effect of colchicine compared with placebo on high sensitivity C-reactive protein in patients with acute coronary syndrome or acute stroke: a pilot randomized controlled trial. J Thromb Thrombolysis 33:88-94. https://doi.org/10.1007/s11239-011-0637-y

17. Nidorf SM, Fiolet ATL, Mosterd A et al (2020) Colchicine in patients with chronic coronary disease. N Engl J Med. https:// doi.org/10.1056/NEJMoa2021372

18. Imazio M, Bobbio M, Cecchi E et al (2005) Colchicine as firstchoice therapy for recurrent pericarditis: results of the CORE (COlchicine for REcurrent pericarditis) Trial. Arch Intern Med 165:1987-1991. https://doi.org/10.1001/archinte.165.17.1987

19. Imazio $M$, Bobbio $M$, Cecchi $E$ et al (2005) Colchicine in addition to conventional therapy for acute pericarditis: results of the COlchicine for acute PEricarditis (COPE) trial. Circulation 112:2012-2016. https://doi.org/10.1161/CIRCULATIO NAHA.105.542738

20. Imazio M, Brucato A, Ferrazzi P et al (2011) Colchicine reduces postoperative atrial fibrillation: results of the colchicine for the prevention of the postpericardiotomy syndrome (COPPS) atrial fibrillation substudy. Circulation 124:2290-2295. https://doi. org/10.1161/CIRCULATIONAHA.111.026153

21. Imazio M, Brucato A, Cemin R et al (2011) Colchicine for recurrent pericarditis (CORP): a randomized trial. Ann Intern Med 155:409-414. https://doi.org/10.7326/0003-4819-155-7-20111 0040-00359

22. Imazio $\mathrm{M}$, Brucato $\mathrm{A}, \mathrm{Cemin} \mathrm{R}$ et al (2013) A randomized trial of colchicine for acute pericarditis. N Engl J Med 369:1522-1528. https://doi.org/10.1056/NEJMoa1208536

23. Imazio M, Brucato A, Ferrazzi P et al (2014) Colchicine for prevention of postpericardiotomy syndrome and postoperative atrial fibrillation: the COPPS-2 randomized clinical trial. JAMA 312:1016-1023. https://doi.org/10.1001/jama.2014.11026

24. Imazio M, Belli R, Brucato A et al (2014) Efficacy and safety of colchicine for treatment of multiple recurrences of pericarditis (CORP-2): a multicentre, double-blind, placebo-controlled, randomised trial. Lancet 383:2232-2237. https://doi.org/10.1016/ S0140-6736(13)62709-9

25. Liebenberg JJ, Dold CJ, Olivier LR (2016) A prospective investigation into the effect of colchicine on tuberculous pericarditis. Cardiovasc J Afr 27:350-355. https://doi.org/10.5830/ CVJA-2016-035

26. Sambola A, Roca Luque I, Mercé J et al (2019) Colchicine administered in the first episode of acute idiopathic pericarditis: a randomized multicenter open-label study. Rev Esp Cardiol (Engl Ed) 72:709-716. https://doi.org/10.1016/j.rec.2018.11.016

27. Deftereos S, Giannopoulos G, Panagopoulou V et al (2014) Antiinflammatory treatment with colchicine in stable chronic heart failure: a prospective, randomized study. JACC Heart Fail 2:131137. https://doi.org/10.1016/j.jchf.2013.11.006 
28. Tabbalat RA, Hamad NM, Alhaddad IA et al (2016) Effect of ColchiciNe on the InciDence of atrial fibrillation in open heart surgery patients: END-AF trial. Am Heart J 178:102-107. https ://doi.org/10.1016/j.ahj.2016.05.006

29. Deftereos S, Giannopoulos G, Kossyvakis C et al (2012) Colchicine for prevention of early atrial fibrillation recurrence after pulmonary vein isolation: a randomized controlled study. J Am Coll Cardiol 60:1790-1796. https://doi.org/10.1016/j.jacc.2012.07.031

30. Bessissow A, Agzarian J, Shargall Y et al (2018) Colchicine for prevention of perioperative atrial fibrillation in patients undergoing lung resection surgery: a pilot randomized controlled study. Eur J Cardiothorac Surg 53:945-951. https://doi.org/10.1093/ejcts lezx422

31. Ozen S, Kone-Paut I, Gül A (2017) Colchicine resistance and intolerance in familial mediterranean fever: definition, causes, and alternative treatments. Semin Arthritis Rheum 47:115-120. https ://doi.org/10.1016/j.semarthrit.2017.03.006

32. Cerquaglia C, Diaco M, Nucera G et al (2005) Pharmacological and clinical basis of treatment of familial mediterranean fever (FMF) with colchicine or analogues: an update. Curr Drug Targets Inflamm Allergy 4:117-124. https://doi.org/10.2174/1568010053 622984

33. Zemer D, Pras M, Sohar E et al (1986) Colchicine in the prevention and treatment of the amyloidosis of familial Mediterranean fever. N Engl J Med 314:1001-1005. https://doi.org/10.1056/ NEJM198604173141601

34. Ozdogu H, Boga C, Yilmaz Z et al (2007) Long-term colchicine therapy in a patient with Behçet's disease and acute promyelocytic leukemia. Rheumatol Int 27:763-765. https://doi.org/10.1007/ s00296-006-0285-2

35. Taylor EW (1965) The mechanism of colchicine inhibition of mitosis. I. Kinetics of inhibition and the binding of H3-COLCHICINE. J Cell Biol 25:145-160. https://doi.org/10.1083/ jcb.25.1.145 (SUPPL)

36. Bhattacharyya B, Panda D, Gupta S, Banerjee M (2008) Antimitotic activity of colchicine and the structural basis for its interaction with tubulin. Med Res Rev 28:155-183. https://doi. org/10.1002/med.20097

37. Chaldakov GN (2018) Colchicine, a microtubule-disassembling drug, in the therapy of cardiovascular diseases. Cell Biol Int 42:1079-1084. https://doi.org/10.1002/cbin.10988

38. Horioka K, Tanaka H, Isozaki S et al (2020) Acute colchicine poisoning causes endotoxemia via the destruction of intestinal barrier function: the curative effect of endotoxin prevention in a murine model. Dig Dis Sci 65:132-140. https://doi.org/10.1007/ s10620-019-05729-w

39. Finkelstein Y, Aks SE, Hutson JR et al (2010) Colchicine poisoning: the dark side of an ancient drug. Clin Toxicol (Phila) 48:407-414. https://doi.org/10.3109/15563650.2010.495348
40. Maxwell MJ, Muthu P, Pritty PE (2002) Accidental colchicine overdose. A case report and literature review. Emerg Med J 19:265-266. https://doi.org/10.1136/emj.19.3.265

41. Kuncl RW, Duncan G, Watson D et al (1987) Colchicine myopathy and neuropathy. N Engl J Med 316:1562-1568. https://doi. org/10.1056/NEJM198706183162502

42. Medani S, Wall C (2016) Colchicine toxicity in renal patients: are we paying attention? Clin Nephrol 86:100-105. https://doi. org/10.5414/CN108343

43. Ridker PM, Everett BM, Thuren T et al (2017) Antiinflammatory therapy with canakinumab for atherosclerotic disease. N Engl J Med 377:1119-1131. https://doi.org/10.1056/NEJMoa1707914

44. Imazio M, Andreis A, De Ferrari GM (2020) COVID-19 and myocardial injury: is there a role for interleukin-1 inhibition? J Cardiovasc Med (Hagerstown) 21:465-466. https://doi.org/10.2459/ JCM.0000000000000998

45. Imazio M, Brucato A, Lazaros G et al (2020) Anti-inflammatory therapies for pericardial diseases in the COVID-19 pandemic: safety and potentiality. J Cardiovasc Med 21:625-629. https:// doi.org/10.2459/JCM.0000000000001059

46. Adler Y, Charron P, Imazio M et al (2015) 2015 ESC guidelines for the diagnosis and management of pericardial diseases: the task force for the diagnosis and management of pericardial diseases of the European society of cardiology (ESC) endorsed by: the European association for cardio-thoracic surgery (EACTS). Eur Heart J 36:2921-2964. https://doi.org/10.1093/eurheartj/ehv318

47. Imazio M (2020) Anti-IL-1 agents: a paradigm shift in medical therapy for recurrent pericarditis? Heart. https://doi.org/10.1136/ heartjnl-2020-318549

48. Yanev S, Zhelyazkova-Savova M, Chaldakov G (2019) The fibrous cap: a promising target in the pharmacotherapy of atherosclerosis. Biomed Rev 30:136-141. https://doi.org/10.14748/bmr.v30.6394

49. Imazio M, Andreis A, Brucato A et al (2020) Colchicine for acute and chronic coronary syndromes. Heart 106:1555-1560. https:// doi.org/10.1136/heartjnl-2020-317108

50. Fujisue K, Sugamura K, Kurokawa H et al (2017) Colchicine improves survival, left ventricular remodeling, and chronic cardiac function after acute myocardial infarction. Circ J 81:11741182. https://doi.org/10.1253/circj.CJ-16-0949

51. Cooper G (2006) Cytoskeletal networks and the regulation of cardiac contractility: microtubules, hypertrophy, and cardiac dysfunction. Am J Physiol Heart Circ Physiol 291:H1003-1014. https:// doi.org/10.1152/ajpheart.00132.2006

Publisher's Note Springer Nature remains neutral with regard to jurisdictional claims in published maps and institutional affiliations. 